\title{
Evaluation of Deformation of Adjacent Buildings With Different Foundation Types Caused by Foundation Pit Excavation Under Combined Support of Isolation Pile and Diaphragm Wall
}

\section{Shaokun Ma}

Guangxi University

\section{Fapai Tian}

Guangxi University

Zhen Huang ( $\square$ hzcsig@163.com )

Guangxi University

Hu Lu

Shenzhen polytechnic

Xiaoxi Fu

Guangxi University

\section{Yu Shao}

Guangxi Xinfazhan Communications Group CO., Ltd

\section{Research Article}

Keywords: Deep foundation pit of subway, Foundation type, Isolation pile, Diaphragm Wall, Support efficiency

Posted Date: November 30th, 2021

DOI: https://doi.org/10.21203/rs.3.rs-1019620/v1

License: (1) This work is licensed under a Creative Commons Attribution 4.0 International License. Read Full License 


\section{Abstract}

The process of excavation and unloading of a deep subway foundation pit will cause deformation of the surrounding buildings. There are significant differences in building deformation due to different methods of supporting the foundation pit and building foundation forms. This study takes the deep foundation pit project of the station as an example to investigate this difference. A three-dimensional numerical finite element model of a deep foundation pit has been established that considers different types of building foundations (independent foundation, box foundation, and pile foundation). The sensitivity of the two supporting methods of the diaphragm wall and the combined support of isolation pile and diaphragm wall regarding the maximum settlement value of the building, the horizontal inclination value, the slope angle, and the foundation angular distortions were analyzed. Finally, the sensitivity of the length of the isolated pile to the maximum settlement value and the horizontal displacement value of different types of building foundations are discussed. The results show that the combined support method of isolation piles and diaphragm walls has the highest supporting efficiency ( $93.5 \%$ of independent foundations and $42.3 \%$ of box foundations) for angular distortions of shallow foundation buildings. The efficiency of pile foundation support is the lowest (31.4\%). For the combined support method of isolation piles and diaphragm walls, the maximum settlement value, and the value of horizontal displacement of the building will decrease with increasing the length of isolation pile. When the depth of isolation pile is greater than $24 \mathrm{~m}$, the settlement deceleration rate of the independent foundation and the pile foundation slows down; when the depth of isolation pile is greater than $27 \mathrm{~m}$, the settlement deceleration rate of the box foundation will slow down, and the deceleration rate of the horizontal displacement of the independent foundation and box foundation will slow down.

\section{Introduction}

With the development of urban subway network, many deep foundation pits of subway stations were built around dense buildings. The process of excavating foundation pits causes deformations of the surrounding soil, and excessive deformation of the soil will damage the surrounding buildings. It is very important to find a reliable support method to control the safety of surrounding buildings. At the same time, different types of building foundations have different degrees of deformation (Tan et al. 2016). Reasonable quantification and evaluation of this difference in deformation have important engineering significance for foundation pit engineering.

Some scholars have conducted many studies on the deformation of surrounding buildings caused by the excavation of foundation pits. Zheng and Li (2012) studied the deformation modes of different envelope structures and suggested that the concave deflection deformation of the building is the most significant when there is skirting and convex deformation of the enclosure structure occurs. Soomro et al. (2019) analyzed the impact of excavation of the foundation pit on adjacent pile foundation in different cases of $H_{e} / L_{p}\left(H_{e}\right.$ is the depth of excavation of the foundation pit and $L_{p}$ is relative to the pile length). Excavation in the case $H_{e} / L_{p}=$ 1.33 resulted in the largest pile settlement, while the largest pile defection was induced in the case $H_{e} / L_{p}=$ 0.67. Maddah et al. (2021) investigated the interaction between the excavation of the pile-anchor supporting foundation pit and the building and showed that the width of the building has little effect on its own rotation, while it has a great influence on the displacement and settlement of the foundation pit. Xu et al. (2021) analyzed the instability modes of buildings under different embedding ratios of supporting structures and 
depths of foundation reinforcement. To ensure the safety of adjacent buildings, the wall inclination should be controlled within $0.05 \%$. Many scholars combine real engineering cases and valuable research has been conducted through on-site monitoring methods. For example, Finno and Bryson (2002) analyzed monitoring data of a three-story teaching building by excavation of a foundation pit. It was determined that when the angular deformation of the building reaches $1 / 940$ and the excavation depth is $5.5 \mathrm{~m}$, cracks are seen for the first time on the concave side of the building. After the completion of the excavation of the foundation pit, the angular deformation of the building reaches $1 / 300$. Fong et al. (2014) analyzed a $23 \mathrm{~m}$ deep basement excavation project near Harrods Department Store in London based on on-site monitoring data. It is believed that the settlement of the building was mainly caused by the construction of the diaphragm wall and piles. Recently, numerical methods have been widely used in the foundation pit excavation simulation due to their significant advantages in processing nonlinear problems and computational efficiency. Zhao et al. (2015) established a three-dimensional finite element model of a foundation pit supported by a diaphragm wall. The influence of the excavation of the foundation pit on the deformation of the building was analyzed, and it is believed that the corner effect of the foundation pit will cause settlement and torsional deformation of the building.

Different forms of the envelope structures have a great influence on the deformation of the building. Taking the diaphragm wall as an example, although its overall rigidity is large, the problem of building damage due to excessive deformation still remains (Tan et al 2018). Therefore, some scholars (Ding et al. 2012) suggested inserting isolation piles behind the diaphragm wall to protect the building. Some numerical methods (Feng et al. 2018; Li et al. 2020; Ying et al. 2012; Bilotta and Russo 2011; Di Mariano et al. 2007) and orthogonal experimental design (Ji et al. 2013) were used for optimizing this type of support parameters. Ma et al. (2021) proposed a combined support method with isolation pile and diaphragm wall to protect buildings adjacent to the foundation pit as it is considered that the maximum deformation of buildings caused by the combined support is $59.1 \%$ less than that caused by the diaphragm wall support. However, most of the existing studies have isolated the influence of the ground connecting wall and the isolation pile support method on the building deformation. The impact on the deformation of a building under the combined support method of isolation piles and diaphragm walls is not considered, while the type of building foundation is relatively individual and the difference in deformation of different foundation types of buildings is ignored.

For that reason, some scholars have conducted an analysis on the type of building foundation. Shi et al. (2018) studied the changes in the total settlement, differential settlement and angular distortions of buildings with strip, box and pile foundations at different distances from the foundation pit. Yu and Geng (2019) performed an indoor test, analyzing changes in horizontal and vertical displacements of buildings with retaining piles of different diameters, different foundation forms (strip and independent foundations), and different distances between buildings and foundation pits. Son and Cording (2011) comparatively analyzed the impact of excavation of a foundation pit on shallow foundations of different structural types (brickbearing, open-frame, and brick-infilled frame structures). The above studies suggest a certain relationship between differences in building deformation caused by excavation of the foundation pit and the type of foundation. However, there is a lack of research on the differences in the deformation of different types of building foundations under the combined support method of isolation piles and diaphragm walls, so this difference in deformation needs to be quantitatively analyzed. 
Given the shortcomings of the above research, this research takes as an example the project of the foundation

pit of Guangxi University Station on the Nanning Metro Line 5. Based on field monitoring data, the deformation characteristics of buildings caused by excavation of the foundation pit under the combined support method of isolation pile and diaphragm wall are analyzed. Based on the measured data, a three-dimensional numerical finite element model was established. The difference between the influence of the two supporting methods of diaphragm wall and the combined support of isolation pile and diaphragm wall on the deformation of adjacent buildings with different foundation types is analyzed. Finally, the sensitivity of the length of the isolated pile to the maximum settlement value and the value of horizontal displacement of different types of building foundations in the combined support method of isolated piles and diaphragm walls are discussed.

\section{Engineering Case}

\section{Project overview}

Guangxi University Station of Nanning Metro Line 5 is an island station with three underground floors. The main support excavation for the station has a length of $156 \mathrm{~m}$ and a width of the standard section of $22.6 \mathrm{~m}$. The foundation pit studied in this paper is in the northeast corner of Guangxi University Station (yellow part in Fig. 1). The shape of the foundation pit is irregular $L$, the excavation depth of the foundation pit is $9.3 \sim 15.3 \mathrm{~m}$, the area is about $1500 \mathrm{~m}^{2}$, the perimeter of the foundation pit is about $110 \mathrm{~m}$, and the width is about $15.5 \mathrm{~m}$. The area around the station mainly consists of 5-storey frame structure buildings $A$ and 13-story frame-shear wall structure building $B$, which are located on the west and east sides, respectively (Fig. 1). Building $A$ has an independent foundation structure, $5.5 \mathrm{~m}$ away from the foundation pit, while building $B$ has a box foundation form, $5.8 \mathrm{~m}$ away from the foundation pit. It is the key protection object of this project as the two buildings are close to the foundation pit with a certain degree of damage. The layout of the foundation pit is shown in Fig. 1.

\section{Design of supporting structure and monitoring}

The foundation pit studied in this paper adopts an underground diaphragm wall $800 \mathrm{~mm}$ thick and three concrete supports. Part of the foundation pit has a plate support. To reduce the impact of the construction of the foundation pit on buildings $A$ and $B$, two buildings close to the side of the foundation pit are equipped with isolation piles. The distance between the diaphragm wall and the isolation piles is $1.6 \mathrm{~m}$ and they are connected by tension beams. The elevations of the three concrete supports are $-0.32 \mathrm{~m},-6.72 \mathrm{~m}$, and $-10.51 \mathrm{~m}$, respectively. Fig. 2 shows the supporting form of a typical section of the foundation pit.

The surrounding environment of the foundation pit is complex. The extent of the impact of the foundation pit excavation is 1 to 4 times greater than the depth of the foundation pit excavation. Monitoring points are arranged in this range and the specific plane layout of the monitoring points is shown in Fig. 3.

\section{Monitoring data analysis}

Buildings $A$ and $B$ are dangerous old buildings close to the foundation pit. Monitoring data of these two buildings are analyzed. The four monitoring points with the largest settlement value of the two buildings during the construction of the foundation pit were selected for analysis. As shown in Fig. 4, upon completion of excavation of the foundation pit, the monitoring point with the largest settlement value of building $\mathrm{A}$ is J6- 
11 , with a settlement value of $6.71 \mathrm{~mm}$. The maximum settlement value of building $B$ is $5.16 \mathrm{~mm}$ monitored at point J7-3. This is less than the settlement control value of $10 \sim 30 \mathrm{~mm}$ of the surrounding structures given in the Code GB50911-2013. Analyzing the law of change of settlement value of the two buildings with the construction steps of the foundation pit, it can be seen that settlement of the buildings in the construction stage of isolation pile and diaphragm wall accounts for $87 \%$ and $88 \%$ of total settlement of the buildings during the construction of the foundation pit, respectively. The impact of the excavation of the foundation pit on the two buildings is far smaller than the former, which indicates that the combined support of the isolation pile and diaphragm wall plays an important role in protecting the buildings adjacent to the foundation pit.

Zheng and Li (2012) considered the law of deformation of the initial settlement of the building during the foundation pit excavation. The results from this study showed that when the building is at the lowest point of the surface settlement curve outside the foundation pit, the tensile strain of the wall perpendicular to the longitudinal wall of the pit increases significantly. Buildings A and B in this study are located near the foundation pit, and the transverse wall and longitudinal walls of Building A are perpendicular to the side of the pit. Therefore, it is necessary to select transverse wall and longitudinal walls in different stages of excavation of the foundation pit for further analysis. The curve of the change in the settlement value of the transverse wall and longitudinal wall building walls is shown in Fig. 5. Although the transverse and longitudinal walls of Building A near the corner of the foundation pit are perpendicular to the side of the pit, the deflection and deformation curves of the walls are different. The transverse wall curve is relatively flat, and the longitudinal wall deflection curve is similar to the ground surface, with concave and convex sections. Analyzing the construction phase of the building, it can be seen that as the excavation of the second soil layer (11/14), the third soil layer (11/30), and the last soil layer (12/7) is completed, the excavation of each soil layer has a great impact on the transverse wall and a small impact on the longitudinal wall. This is because one side of the transverse wall is located at a deeper depth of the excavation of the foundation pit, so its settlement value is largest. The deflection values of the transverse and longitudinal walls of the building $A$ are $0.1 \%$ and $0.8 \%$, respectively. Although the longitudinal wall of building $B$ is not perpendicular to the side of the foundation pit, after excavation of the foundation pit is completed, the longitudinal wall has a groove settlement form with a deflection value of $0.06 \%$.

In summary, the combined support method of isolation piles and diaphragm walls has a good protective effect on Buildings $A$ and $B$. There is a certain degree of difference in the deformation of the walls of these buildings. To further investigate the difference in deformation of different types of building foundations by the combined support method, the finite element numerical analysis models are established. In order to maintain the consistency of the variables and reduce the interference of other factors, only the foundation form of Building A will be transformed.

\section{Numerical Modeling}

\section{Soil constitutive model}

A large number of on-site measured data and numerical simulations (Burland 1989; Jardin et al.1986; Mair 1993) show that when soil mass is disturbed in geotechnical engineering, it will undergo small deformations and will have small strain, with a certain relationship between the soil stiffness and the strain. The common 
strain level of geotechnical engineering is shown in Fig. 6 . The engineering strain of the foundation pit is $0.01 \sim 1 \%$, which belongs to the small strain range. The soil small strain model (HSS) (Benz 2006) can well reflect the nonlinear and stress-related characteristics of the soil small strain, so HSS is selected as the constitutive model in this study.

Table 1 shows the mechanical parameters of the soil. Where Gref 0 is the initial dynamic shear modulus of the soil, $Y_{0.7}$ is the shear strain at which the shear modulus decays to $70 \%$ of the initial shear modulus, Eref oed is the secant modulus measured by the triaxial consolidation drained shear test, Eref ur is the loading and unloading modulus measured by the triaxial consolidation drained shear test, and Eref oed is the tangent modulus under the reference stress determined by the standard consolidation test. The value of $\gamma_{0.7}$ is 0.00011 according to Brinkgreve and Broere (2006), and Gref 0 is 2.5 4.9 Eref ur. According to the PLAXIS 3D software manual and existing engineering experience, the values of Eref 50 and Eref oed are basically the same, Eref ur is generally 2 4 times larger than the loading modulus (the model in this study takes 3 times), and $c$ and $\varphi$ of the soil are taken from the geotechnical survey report of this project.

Table 1 Physical and mechanical properties of soil and the parameters for numerical simulation

\begin{tabular}{|c|c|c|c|c|c|c|c|c|c|}
\hline \multirow[t]{2}{*}{ Soil type } & \multirow[t]{2}{*}{$h(\mathrm{~m})$} & \multirow{2}{*}{$\begin{array}{l}\rho \\
\left(\mathrm{kN} / \mathrm{m}^{3}\right)\end{array}$} & \multirow{2}{*}{$\begin{array}{l}c \\
(\mathrm{kPa})\end{array}$} & \multirow{2}{*}{$\begin{array}{l}\varphi \\
\left(^{\circ}\right)\end{array}$} & \multicolumn{5}{|c|}{ Numerical simulation parameters } \\
\hline & & & & & $\begin{array}{l}\text { Gref } \\
O(\mathrm{Mpa})\end{array}$ & $Y_{0.7}\left(10^{-3}\right)$ & $\begin{array}{l}\text { Eref } \\
50(\mathrm{Mpa})\end{array}$ & $\begin{array}{l}\text { Eref } \\
\text { oed(Mpa) }\end{array}$ & $\begin{array}{l}\text { Eref } \\
\text { ur(Mpa) }\end{array}$ \\
\hline${ }_{2}$ Fill & 5.2 & 19.5 & 15 & 10 & 50 & 0.11 & 6 & 6 & 18 \\
\hline $\begin{array}{l}3-2 \text { Silt } \\
\text { clay }\end{array}$ & 4.9 & 19.4 & 25.0 & 14.0 & 80 & 0.11 & 8 & 8 & 24 \\
\hline Silt & 1.2 & 20 & 11.0 & 15.0 & 80 & 0.11 & 12 & 12 & 36 \\
\hline 1-1 Gravel & 12.5 & 19.6 & 0 & 34 & 400 & 0.11 & 50 & 50 & 150 \\
\hline${ }_{2}^{1-}$ Sandrock & 2.7 & 21 & 70 & 22 & 400 & 0.11 & 48 & 48 & 144 \\
\hline${ }_{3}^{1-}$ Sandrock & 33.5 & 21.1 & 90.0 & 25.0 & 500 & 0.11 & 52.5 & 52.5 & 157.5 \\
\hline
\end{tabular}

\section{Numerical model and material parameters}

A deep foundation pit of Nanning Metro Line 5 in Guangxi is taken as the case study. The PLAXIS software is used to build a three-dimensional finite element calculation model. The range of soil settlement behind the wall caused by the excavation of the foundation pit is four times the depth of the excavation of the deep foundation pit. Given the influence of the boundary effect, this model conducted full-scale modeling. The size of the model is $280 \mathrm{~m}$ (length) $\times 240 \mathrm{~m}$ (width) $\times 60 \mathrm{~m}$ (height). The isolation pile of the foundation pit is simplified to the plate element using the principle of stiffness equivalence (Atkinson et al. 1990), and the simplified formula is as follows: 
$\frac{1}{64} \pi D^{4}=\frac{1}{12}(D+t) h^{3}$

where, $D$ is the diameter of the isolated piles, $t$ is the distance between the isolated piles, and $h$ is the thickness of the equivalent wall thickness. The value of $t$ is $0.623 \mathrm{~m}$ and is calculated by Eq. 1 . The concrete internal support is simulated by beam elements, and the contact relationship between ground connecting walls and isolation piles and soil is simulated by interface elements. The three-dimensional numerical model is constrained and fixed at the bottom, and the other four sides are set with normal constraints that allow only vertical displacement of the model. The mesh is refined in places where the structural stress is concentrated. The bottom of the three-dimensional numerical model is restrained and fixed, and normal constraints are placed on the other four sides, so only the vertical displacement of the model occurs. Fig. 7 shows the overall mesh division of the model.

The floor slabs of Buildings A and B are simulated by linear elastic model plate elements, the pillars are beam elements, and the pile elements are simulated by embedded beam elements. The depth of the pile foundation is $14 \mathrm{~m}$. Table 2 shows the specific parameters of the building.

Table 2 Building material parameters

\begin{tabular}{|llll|}
\hline Material & $\gamma\left(\mathrm{kN} / \mathrm{m}^{3}\right)$ & $E(\mathrm{Mpa})$ & $d(\mathrm{~m})$ \\
\hline Floor & 25 & 30 & 0.1 \\
\hline Foundation slab & 25 & 30 & 1.5 \\
\hline Pillar & 25 & 30 & $/$ \\
\hline Foundation side wall & 25 & 30 & 0.2 \\
\hline Raft & 25 & 30 & 0.3 \\
\hline Pile foundation & 5.14 & 30 & 0.6 \\
\hline
\end{tabular}

\section{Simulation scheme}

The simulated construction steps are as follows. Step 1 generates an initial stress field; Step 2 activates the surrounding buildings; Step 3 activates the diaphragm wall and the isolation piles; Step 4 excavates the first layer of soil (-1.67 m); Step 5 activates the first support; Step 6 excavates the second layer of soil (-6.67 $\mathrm{m})$; Step 7 activates the second support; Step 8 excavates the third layer of soil $(-10.67 \mathrm{~m})$; Step 9 activates the third support; and Step 10 completes the excavation of the foundation pit $(-15.3 \mathrm{~m})$.

\section{Model validation}

Fig. 8 shows the results of the simulation and on-site monitoring of the lateral displacement of the diaphragm wall and the ground settlement value. From Fig. 8(a) it can be seen that after the completion of the excavation of the foundation pit, the measured maximum lateral displacement of the diaphragm wall does not differ much from the simulated values, which are $0.06 \% H$ and $0.07 \% H$, respectively. The deformation trends are inward and convex, while the maximum lateral displacement position of the ground connecting wall is slightly 
higher than the bottom of the pit. After the completion of the excavation of the foundation pit, the measured maximum value of the D45-3 profile does not differ much from the calculated value of the simulated value, which are $0.05 \% H$ and $0.04 \% H$, respectively. The deformation trends have surface groove shapes. Combined with the on-site measured data, these results show that the model is reliable.

Hsieh and Ou (1998) provided a method for predicting the form of a surface subsidence groove, proposing a main influence area and a secondary influence area. The main affected area is $0 \sim 2 \mathrm{He}\left(H_{e}\right.$ is the excavation depth of the foundation pit), the secondary affected area is $2 \sim 4 H_{e}$ and the maximum settlement occurs at a distance of $0.5 H_{e}$ from the foundation pit edge. Ou (2002) revised the Hsieh experience curve through numerical calculation and actual measurements. This study showed that the scope of the main affected area is not directly related to the excavation depth of the foundation pit, but is determined by the excavation depth, the excavation width, and the hard soil layer depth. As shown in Fig. 9, $d$ is the distance from the edge of the foundation pit, $P I Z$ is the main affected area of surface settlement, $\delta_{v}$ is the value of surface settlement, and $\delta_{v m}$ is the maximum value of surface settlement. After correction, the settlement value at the boundary point of the main influence area and the secondary influence area is $1 / 6$ of the maximum settlement value, while the distance between the maximum settlement point of the groove shape and the wall of the enclosure is $1 / 3$ of the width of the main affected zone. The surface settlement curve after the foundation pit excavation is in line with the revised curve of Ou's experience curve, and the maximum surface settlement is located on $1 / 3$ of the main affected area, which further verifies the model reliability.

\section{Building deformation characteristics}

To investigate the different influences of two support methods of the diaphragm wall and the combined support method of isolation pile and diaphragm wall on the deformation of different types of building foundations, the following two cases were considered in the numerical simulation. Case 1 is when only the diaphragm wall is used as the retaining structure. Case 2 is the diaphragm wall + isolation pile as the retaining structure. Unless otherwise specified, the deformation values of the buildings are all from the excavation to the bottom of the pit. The support efficiency is defined (Zheng et al. 2018) to quantitatively analyze the deformation of the two schemes:

$$
\eta=\frac{i_{1}-i_{2}}{i_{1}}
$$

where, $i_{7}$ is the evaluation index of building safety, such as the maximum settlement value and the maximum horizontal inclination value of the building for Case 1 , and $i_{2}$ is the building safety evaluation index, such as the maximum settlement value and the maximum horizontal displacement value for Case 2. Therefore, when $\eta$ $(0 \leq \eta \leq 1)$ is larger, it indicates that the combined support method of isolation pile and diaphragm wall is better.

\section{Maximum settlement}

The curve of the change in the maximum settlement value of different types of building foundation is shown in Fig 10. When the excavation depth of the foundation pit is shallow, excavation of the first and second soil layers, the combined support method of isolation piles and diaphragm walls shows no obvious effect on the 
maximum settlement value of each building foundation. When excavating the third soil layer, The support efficiency of the maximum settlement value of independent, box, and pile foundation buildings are $41.4 \%$, $38.5 \%$, and $21.0 \%$, respectively. When excavating the last soil layer, the maximum settlement support efficiency for each type of building foundation is $34 \%, 32 \%$, and $14 \%$, respectively. The support efficiency of the combined support method for the maximum settlement value of each type of building foundation does not increase with increasing the excavation depth of the foundation pit. The excavation depth is $10.67 \mathrm{~m}$ (the third layer of soil), which shows the best supporting effect on each building foundation. Comparing the support efficiency of isolation pile diaphragm wall to various foundation types, the combined support method shows the best support effect on the settlement value of independent and box foundations, with small difference in the support efficiency, followed by pile foundation buildings.

\section{Horizontal tilt}

The building tilts into the pit due to the excavation of the foundation pit. The higher the floor, the higher the tilt value. The particularly high-rise frame structures are the most sensitive to the value of the tilt. Rankin (1988) proposed $1 / 500$ as the critical slope value that can damage the building. The maximum horizontal displacement in the $u_{\mathrm{x}}$ and $u_{\mathrm{y}}$ directions of different types of building foundations is taken for analysis (Fig. 11). In the $u_{\mathrm{x}}$ direction, the supporting efficiency of the horizontal inclination value of the isolation and diaphragm wall for dependent, box, and pile foundations is $34.7 \%, 35.8 \%$, and $14.7 \%$, respectively. In the $u_{y}$ direction, these values are $40.5 \%, 42.9 \%$, and $14.1 \%$, respectively. The combined support of the isolation pile and the diaphragm wall shows a small difference in the support efficiency of the pile foundation. For shallow foundation, the value of horizontal inclination in the $u_{y}$ direction shows a better support, and there is little difference in the horizontal displacement of the pile foundation in two directions. buildings with the pile foundation have a good ability to adjust uneven settlement. Under the action of excavation of the foundation pit, their own horizontal displacement is small, so the control efficiency in the $u_{x}$ and $u_{y}$ directions is not very different.

\section{Differential settlement}

Differential settlement of the foundation will cause additional stress on the building structure and will damage it. The frame structure is especially sensitive to differential settlement and deformation (Xin et al. 2011). The slope angle of the building (settlement difference/length of the building) can be calculated through the differential settlement of the building. Bjerrum (1963) found that if the slope angle of a building is greater than $1 / 500$, it will affect the stability of the building. Therefore, it is necessary to study the support efficiency of the combined support method for the slope angle of the building. The settlement values of the short and long sides of the building are shown in Fig. 12. The supporting efficiency of the combined support method of isolation pile and diaphragm wall for a short slope angle of buildings for dependent, box, and pile foundation is $55.5 \%, 52.3 \%$, and $20.8 \%$, respectively. The supporting efficiency of the long slope angle of each basic building is $64.2 \%, 40.7 \%$, and $9.3 \%$, respectively. For independent foundations and box foundations, the supporting efficiency is far higher than with pile foundations. Relative to the settlement value and inclination value of the building, the combined supporting method has the best effect on the slope angle of the building. From the analysis of scope angle, the control scope of the long side of the independent foundation is much larger than that of the box and pile foundations. 


\section{Angular distortions}

After the excavation of the foundation pit, the foundation will tilt and be damaged. Angular distortions can be used as a measure of the degree of damage to a building. The angular distortion is shown in Fig. 13. $A, B, C$, and $D$ are the positions of the corners before the excavation of the building foundation; $E, F, G$, and $H$ are the positions after the foundation settlement due to excavation of the foundation pit; the angles between the sides and horizontal plane after settlement are marked as $a, \beta, \gamma, \delta$; and the tangent of the four included angles is the foundation angular distortions.

The angular distortions of different types of building foundations according to two different support methods are shown in Table 3. From Table 3, the combined support method all protects the angular distortions of the four sides of different foundation types, but the degree of impact is different. The supporting effect of the independent and box foundations is more obvious, while the control effect of the pile foundation is not obvious. For the independent foundation, the combined support method most obviously controls the angular distortions of the angle $\beta$, and the supporting efficiency reaches $93.5 \%$. For the box foundation, the combined support method most obviously controls the angular distortions of the angle $a$, and the supporting efficiency is $42.3 \%$. Finally, for the pile foundation, the angular distortions of the angle $\delta$ controlled by the combined support method are the most obvious and the support efficiency reaches $31.8 \%$.

Table 3 Results of angular distortions of different foundation types

\begin{tabular}{|llllll|}
\hline Foundation type & Support method & \multicolumn{4}{l}{ Angular distortion } \\
\cline { 2 - 6 } & & $a$ & $\beta$ & $\gamma$ & $\delta$ \\
\hline Independent foundation & Case 2 & $9.2 \times 10^{-5}$ & $8.5 \times 10^{-5}$ & $4.5 \times 10^{-5}$ & $9.3 \times 10^{-5}$ \\
\cline { 2 - 6 } & Case 1 & $1.6 \times 10^{-4}$ & $1.1 \times 10^{-3}$ & $4.9 \times 10^{-5}$ & $2.6 \times 10^{-4}$ \\
\hline Box foundation & Case 2 & $7.7 \times 10^{-5}$ & $5.97 \times 10^{-5}$ & $4.8 \times 10^{-5}$ & $1 \times 10^{-4}$ \\
\cline { 2 - 6 } & Case 1 & $1.36 \times 10^{-4}$ & $7.36 \times 10^{-5}$ & $4.96 \times 10^{-5}$ & $2.13 \times 10^{-4}$ \\
\hline Pile foundation & Case 2 & $5.76 \times 10^{-5}$ & $3.9 \times 10^{-5}$ & $1.22 \times 10^{-5}$ & $6.07 \times 10^{-5}$ \\
\cline { 2 - 6 } & Case 1 & $7.3 \times 10^{-5}$ & $4.2 \times 10^{-5}$ & $1.32 \times 10^{-5}$ & $8.86 \times 10^{-5}$ \\
\hline
\end{tabular}

\section{Sensitivity Analysis of Isolation Pile Length}

In general, an isolation pile must be inserted under the sliding surface to have a better protection effect. Therefore, the length of the isolation pile and plane position are the main design parameters of the isolation pile. In theory, the closer the isolation pile is to the building, the better the protection effect (Ying et al. 2012). This section mainly discusses the sensitivity of length of the isolated pile to different types of building foundations under the combined support method. To facilitate the practical application of the project, the maximum settlement value, and the maximum value of horizontal displacement of different types of building foundations are selected as sensitivity indicators. As shown in Fig. 14, the maximum settlement and the maximum horizontal displacement of the building decrease with increasing length of the isolation pile. 
However, there are differences in the amplitude of deformations of each building foundation. The settlement value and horizontal displacement curve of independent and box foundations are steeper than those of the pile foundations, which indicates that buildings with shallow foundations are more sensitive to the length of isolated piles under the combined support method. The change curve of each type of foundation can be roughly divided into diminishing, rapid diminishing, and slow diminishing stages. In addition, the magnitude of the settlement decreases and the horizontal displacement of the building with increasing the pile length is not always the same. For the settlement value and horizontal displacement value of the independent and box foundations, the length of the isolated pile is $\geq 24 \mathrm{~m}, \geq 27 \mathrm{~m}$, respectively, and the reduction rate becomes slow. For the settlement value of the pile foundation, the isolation pile length is $>24 \mathrm{~m}$ and the reduction rate is slower. Regarding the horizontal displacement value of the pile foundation, the reduction rate is not much different.

When the calculation results are normalized (Fig. 15), $y$ is the maximum settlement value and the maximum horizontal displacement value of the building when the length of the isolation pile is changed within the range of 15-36 m; $y_{\max }$ is the maximum settlement value and the maximum horizontal displacement value of the building without isolation piles; $h_{0}$ is the excavation depth of the foundation pit and $h$ is the depth of the isolation pile in the soil.

The supporting efficiency of the combined support method for each type of foundation is shown in Fig. 15. As the depth of the isolation piles increases, the maximum settlement value of the independent and box foundations can be reduced to about $48 \%$ of that without isolation piles. For the pile foundations, it is about $60 \%$. The maximum horizontal displacement that can be reduced by the independent and box foundations is about $57 \%$ of that without isolation piles. For the pile foundations, it is about $73 \%$. The maximum settlement value of buildings with different foundation types, the horizontal displacement value and the isolation pile depth can be uniformly described as follows:

$$
y=y_{\max }\left(A e^{-B \frac{h}{h_{0}}}+C\right)
$$

where, $A, B$, and $C$ are parameters, and the value size is shown in Fig. 15.

Considering the above research, the combined support method shows a small difference in the shallow foundation support. In the actual construction process, it is necessary to comprehensively assess the safety status and foundation types of the buildings adjacent to the foundation pit.

\section{Conclusion}

(1) The influence of the diaphragm wall and the combined support method of isolation pile and diaphragm wall on the deformations of different types of building foundation is studied. The maximum settlement value, horizontal inclination, slope angle, and angular distortions of buildings are selected as the indices of building deformation. The results show that the combined support method has the highest support efficiency for shallow foundations such as independent and box foundations, followed by pile foundation. 
(2) The combined support method of isolation pile and diaphragm wall has the best support effect on the differential settlement of buildings. The support efficiency of short slope angle of buiding for dependent, box, and pile foundation is $55.5 \%, 52.3 \%$, and $20.8 \%$, respectively, and that of long slope angle is $64.2 \%, 40.7 \%$, and $9.3 \%$, respectively. For the independent foundation, the $\beta$ angular distortions support efficiency is the most obvious, and the support efficiency reaches $93.5 \%$; for the box foundation, the $a$ angular distortions support efficiency is the most obvious, and the support efficiency is $42.3 \%$; for the pile foundation, the $\delta$ angular distortions support efficiency is the most obvious, and the support efficiency reaches $31.8 \%$.

(3) The influence of the length of the isolation pile on the maximum settlement and horizontal displacement of different types of building foundations under the combined support method of isolation pile and diaphragm wall is studied. The maximum settlement and horizontal displacement of different types of building foundations corresponding to different isolation pile lengths can be uniformly described by the index function. When compared to the case without the isolation pile support. By increasing the soil depth of the isolation pile, the combined support method can reduce the maximum settlement of the independent and box foundations by about $48 \%$ and for the pile foundation by about $60 \%$. The isolation pile can reduce the maximum horizontal displacement of the independent and the box foundations by about $57 \%$ and for the pile foundation by about $73 \%$.

\section{Declarations}

\section{Acknowledgements}

The authors would like to acknowledge the financial supports from National Natural Science Foundation of China (Nos.51678166) and the Guangxi Key Project of Nature Science Foundation (No.2020GXNSFDA238024)

\section{Author contributions}

Shaokun Ma: Conceptualization, Methodology, Supervision, Project administration. Fapai Tian: Software, Data processing, Writing, Original draft. Zhen Huang: Methodology, Formal analysis, Writing - review \& editing. Hu Lu: Methodology, Software, Data processing. Xiaoxi Fu: Validation, Formal analysis. Yu Shao: Formal analysis, Writing - review \& editing.

Conflict of interest There are no conficts of interest to declare.

\section{References}

Atkinson JH, Richardson D, Stallebrass SE (1990) Effect of recent stress history on the stiffness of overconsolidated soil. Geotechnique 40(4): 531-540

Benz T (2006) Small-strain stiffness of soils and its numerical consequences Ph D Thesis Germany: University of Stuttgart. Stuttgart

Bilotta E, Russo G (2011) Use of a line of piles to prevent damages induced by tunnel excavation. Journal of Geotechnical and Geoenvironmental Engineering 137(3): 254-262 
Bjerrum L (1963) Allowable settlement of structures. In: Proceeding of European Conference on Soil Mechanics and Foundation Engineering, Wiesbaden, Germany 3: 135-137

Brinkgreve RBJ, Broere W (2006) Plaxis material models manual. Delft

Burland JB (1989) Small is beautiful-the stiffness of soils at small strains, Ninth Laurits Bjerrum memorial lecture. Canadian Geotechnical Journal 26(4): 499-516

Di MA, Gesto JM, Gens A, Schwarz H (2007) Ground deformation and mitigating measures associated with the excavation of a new Metro line. Proc. XIV European Conference on Soil Mechanics and Geotechnical Engineering, ECSMGE: 1901-1906

Ding YC, Cheng ZK, Wang JH, Xu AJ, Li YL (2012) Influence of deep excavation on deformation and control of adjacent historical building. Chinese Journal of Geotechnical Engineering 34(S1): 644-648

Feng CL, Zhang DL, Fang Q, Hou YJ (2018) Research on diaphragm wall mechanism and effect of deformation control in soft soil.Chinese Journal of Geotechnical Engineering 40(11): 2087-2095

Finno RJ, Bryson LS (2002) Response of building adjacent to stiff excavation support system in soft clay. Journal of Performance of Constructed Facilities 16(1): 10-20

Fong FH, Standing JR, Bourne-Webb PJ (2014) Building response to adjacent deep basement construction.Proceedings of the Institution of Civil Engineers-Geotechnical Engineering 167(2): 130-143

Ying HW, Li T, Wang WF (2012) Optimization design of partition wall in deep excavations based on 3-d numerical simulation. Rock and Soil Mechanics 33(1): 220-226

Yu S, Geng Y (2019) Influence analysis of underground excavation on the adjacent buildings and surrounding soil based on scale model test. Advances in Civil Engineering 2019: 1-15

Hsieh PG, Ou CY (1998) Shape of ground surface settlement profiles caused by excavation. Canadian Geotechnical Journal 35(6): 1004-1017

Jardine RJ, Potts DM, Fourie AB, Burland JB (1986) Studies of the influence of non-linear stress-strain characteristics in soil-structure interaction. Geotechnique 36(3): 377-396

Ji XB, Zhao W, Li SG, Zhou ZS (2013) Application of isolation piles on metro tunnel for side-crossing the buildings with shallow foundation. Journal of Northeastern University (natural science) 34(1): 135

Li Z, Han M, Liu L, Li Y, Yan S (2020) Corner and partition wall effects on the settlement of a historical building near a supported subway excavation in soft soil. Computers and Geotechnics 128: 103805

Ma SK, Fu XX, Lu H, Huang Z, Zhang JB (2021) A combined support method of isolation pile and diaphragm wall for protection of buildings adjacent to deep foundation pit. Arabian Journal of Geosciengces 14(19): 1-12

Maddah A, Soroush A, Shafipour R (2021) A new concept for interpretation of building-excavation interaction in 3d conditions. Tunnelling and Underground Space Technology 109: 103757 
Mair RJ (1993) Developments in geotechnical engineering research: application to tunnels and deep excavations. In Proceedings of institution of civil engineers: civil engineering 93: 27-41

Ou ZU (2002) Analysis and design theory and practice of deep excavation engineering. Taipei: Science and Technology Books Co.Ltd, 2002

Soomro MA, Mangnejo DA, Bhanbhro R, Memon NA, Memon MA (2019) 3D finite element analysis of pile responses to adjacent excavation in soft clay: Effects of different excavation depths systems relative to a floating pile. Tunnelling and Underground Space Technology 86: 138-155

Shi YZ, Zhao HL, Li XF, Lin SZ (2018) Numerical analysis of the influence of deep excavations on neighboring buildings with different types of foundations. Science Technology and Engineering 18(22): 261-270

Son M, Cording EJ (2011) Responses of buildings with different structural types to excavation-induced ground settlements. Journal of Geotechnical and Geoenvironmental Engineering 137(4): 323-333

Tan Y, Huang R, Kang Z, Bin W (2016) Covered semi-top-down excavation of subway station surrounded by closely spaced buildings in downtown Shanghai. building response. Journal of Performance of Constructed Facilities 30(6): 04016040

Tan Y, Jiang W, Luo W, Lu Y, Xu C (2018) Longitudinal sliding event during excavation of feng-qi station of Hangzhou metro line 1: Postfailure investigation. Journal of Performance of Constructed Facilities 32(4): 04018039

Jia Qiang, Cheng LL, Zhang X (2011) Experimental study of the influence of differential settlement on RC frame structures. China Civil Engineering Journal 44(11): 78-86

Xu C, Yang K, Fan X, Ge J, Jin L (2021) Numerical investigation on instability of buildings caused by adjacent deep excavation. Journal of Performance of Constructed Facilities 35(5): 04021040

Ying HW, Li T, Yang YW, Xie XY (2011) Effect and application of partition walls in protecting adjacent buildings from deep foundation pits. Chinese Journal of Geotechnical Engineering 33(7): 1123-1128

Ying HW, Li T, Wang WF (2012) Optimization design of partition wall in deep excavations based on 3-d numerical simulation. Rock and Soil Mechanics 33(01): 220-226

Yu S, Geng Y (2019) Influence analysis of underground excavation on the adjacent buildings and surrounding soil based on scale model test. Advances in Civil Engineering 2019: 1-15

Zhao W, Chen C, Li S, Pang Y (2015) Researches on the influence on neighboring buildings by concave and convex location effect of excavations in soft soil area. Journal of Intelligent and Robotic Systems 79(3): 351369

Zhen G, Li ZW (2012) Comparative analysis of responses of buildings adjacent to excavations with different deformation modes of retaining walls. Chinese Journal of Geotechnical Engineering 34(6): 969-977 
Zheng G, Li ZW (2012) Finite element analysis of responses of building adjacent to excavation considering initial differential settlement. Rock and Soil Mechanics 33(8): 2491-2499

Zheng G, Wang FJ, Du YM, Diao Y, Lei YW, Cheng XS (2018) The efficiency of the ability of isolation piles to control the deformation of tunnels adjacent to excavations. International Journal of Civil Engineering 16(10): $1475-1490$

\section{Figures}

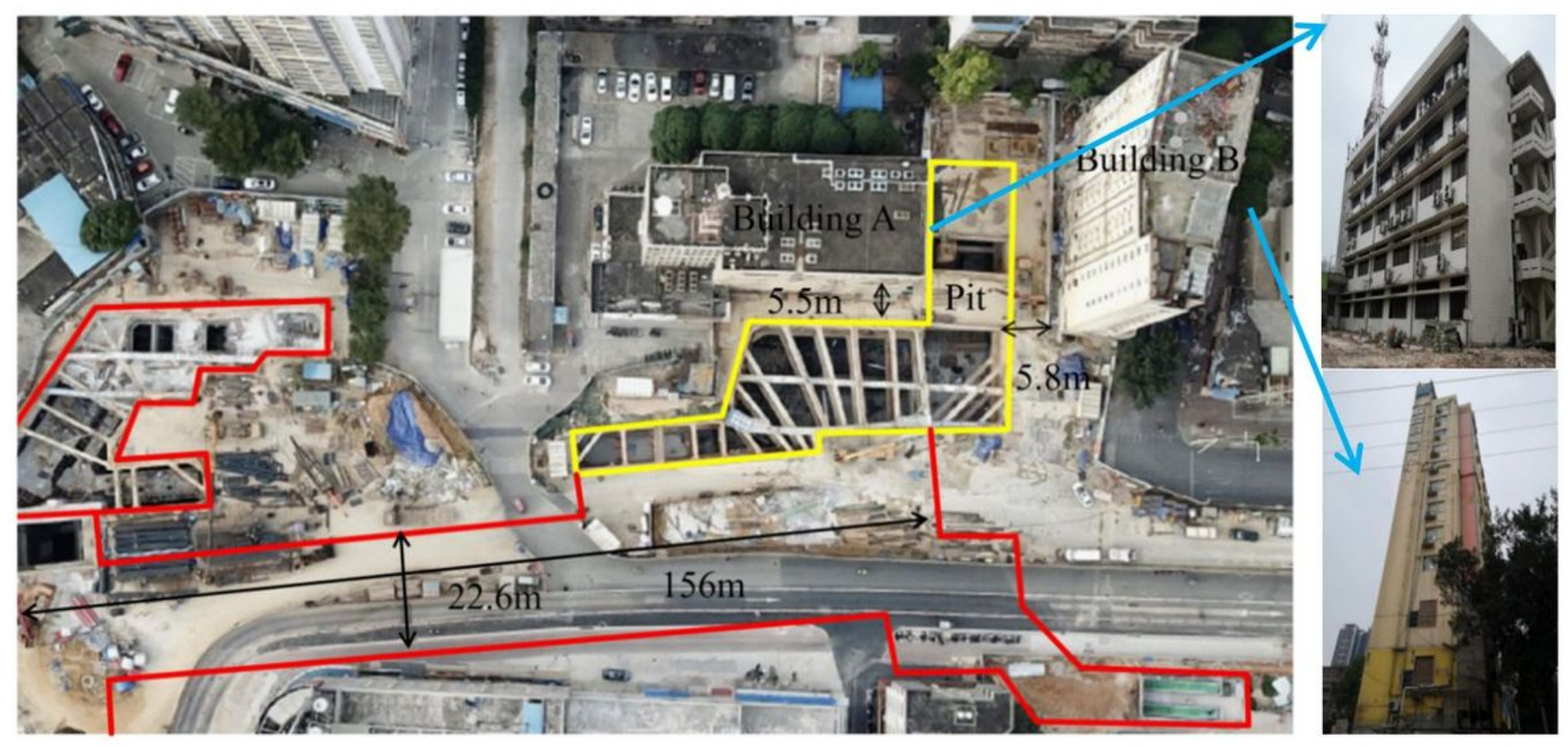

Figure 1

Plane position of foundation pit 


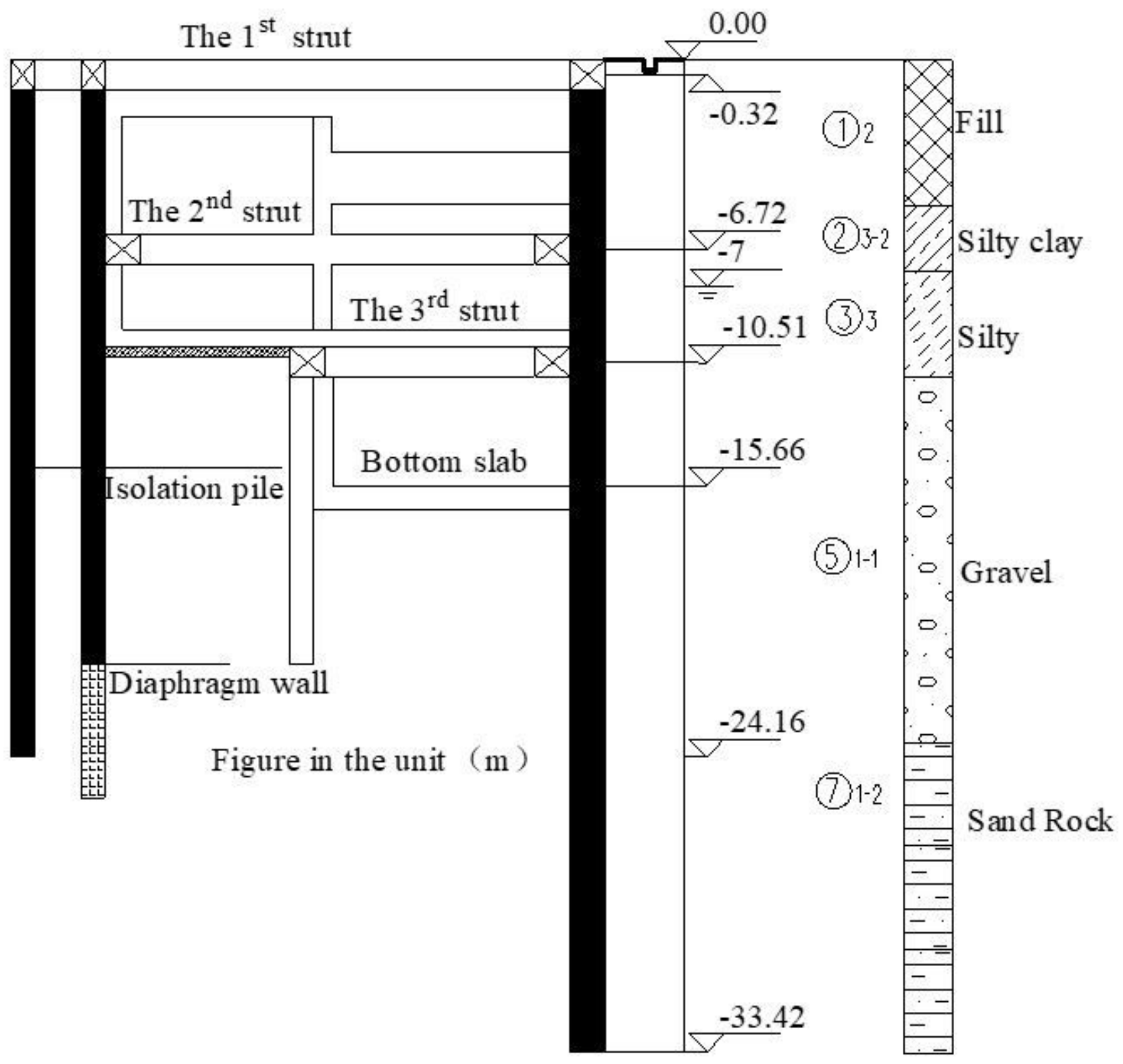

Figure 2

Profile of the braced excavation structure 


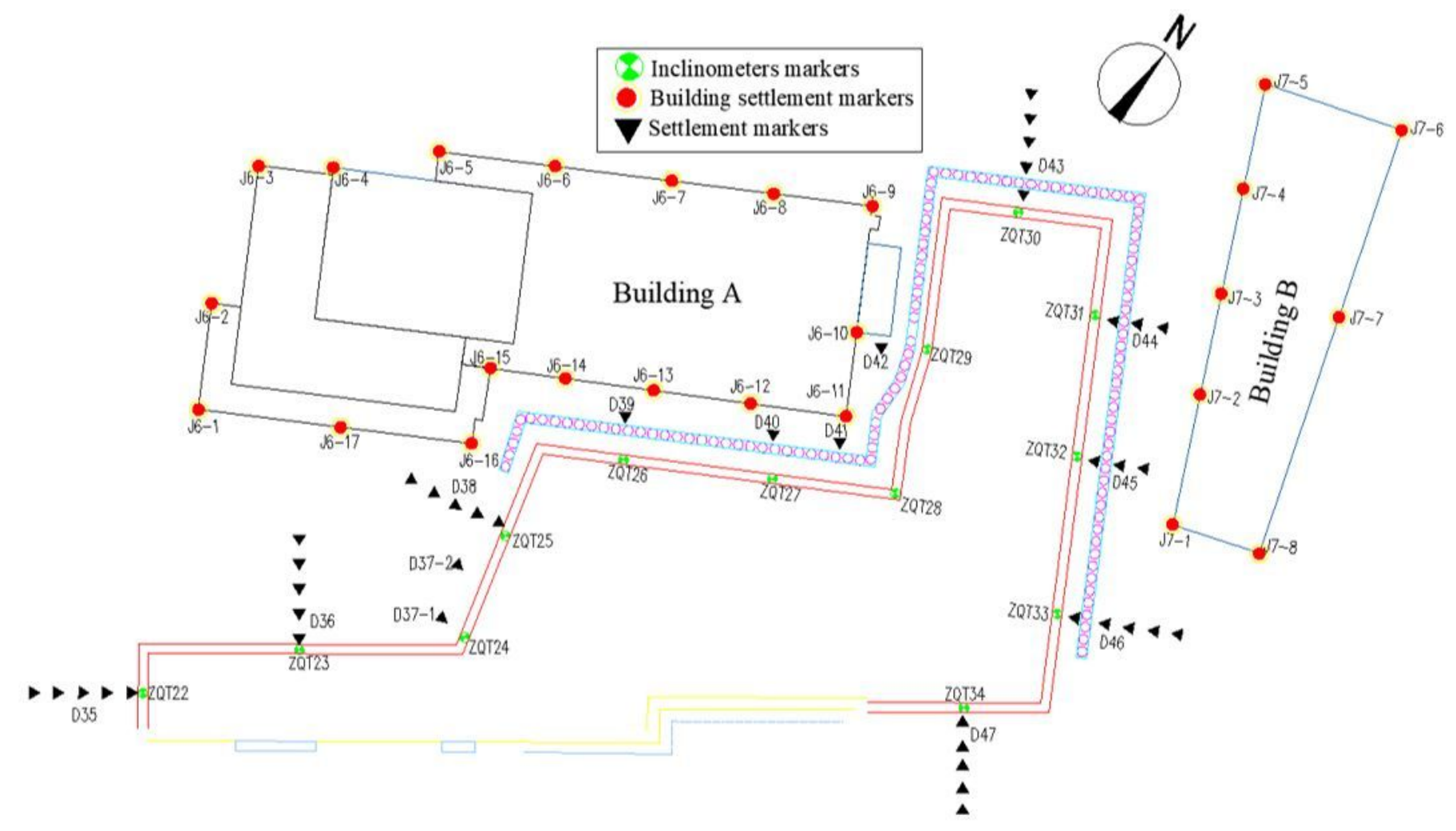

Figure 3

Monitoring items and the layout arrangement plans

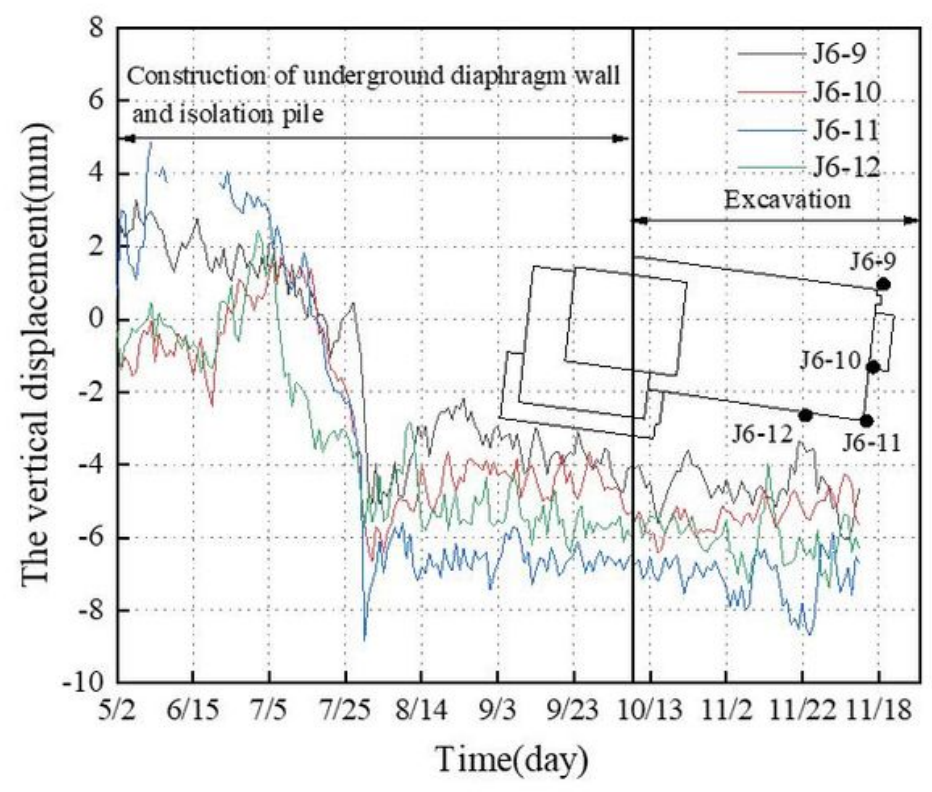

(a) Building A

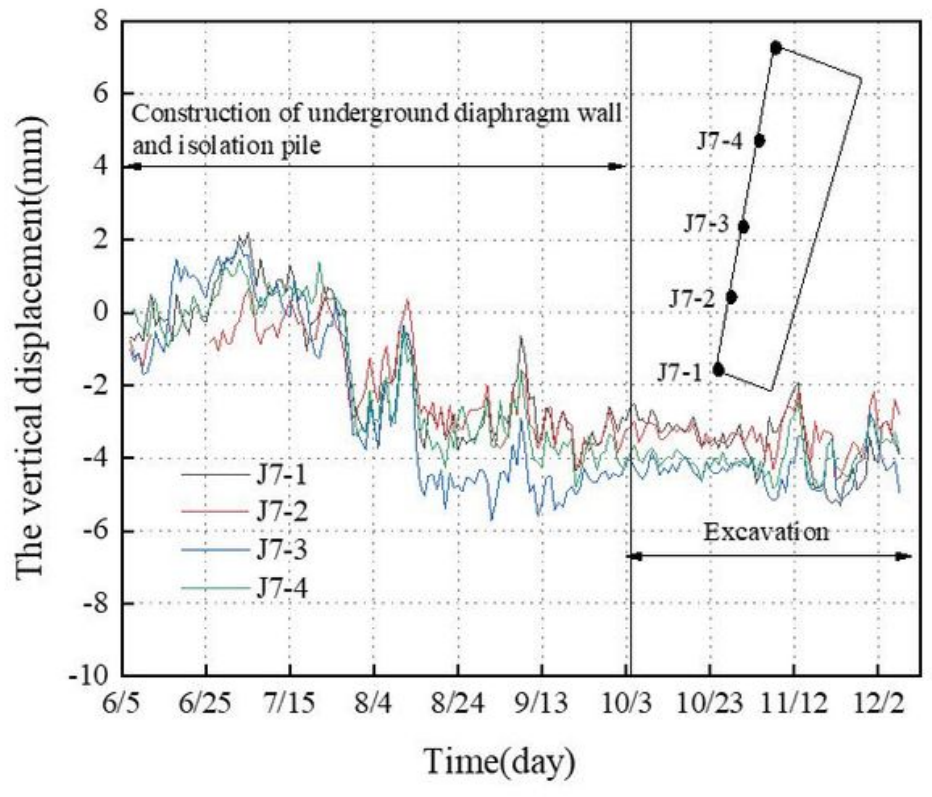

(b) Building B

\section{Figure 4}

Vertical displacement of buildings 


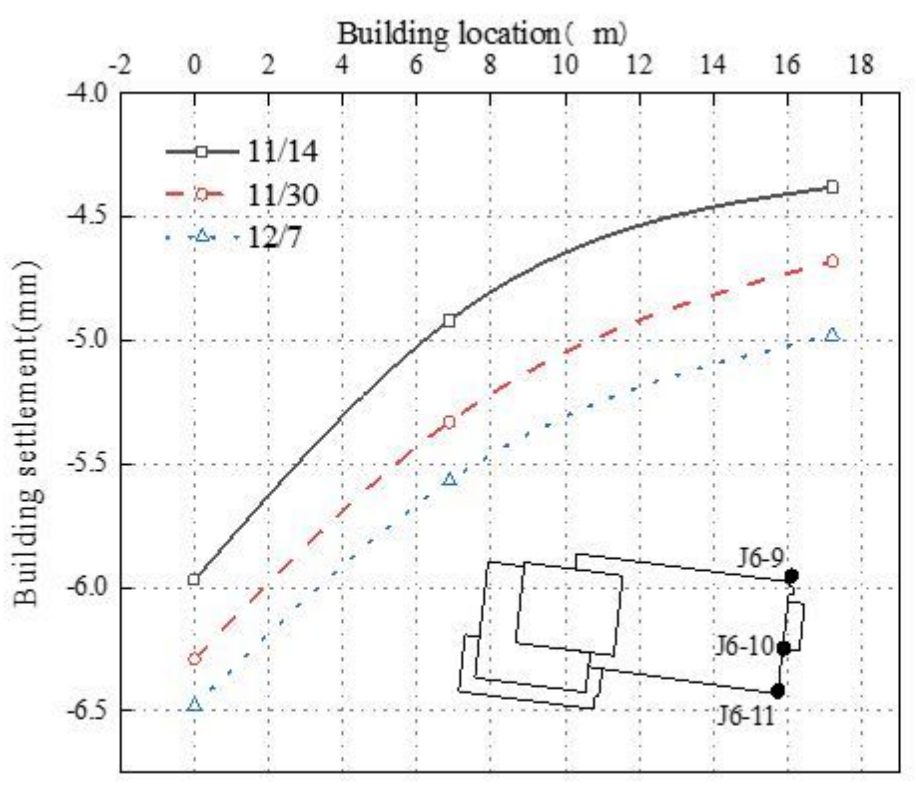

(a) Transverse wall of building A

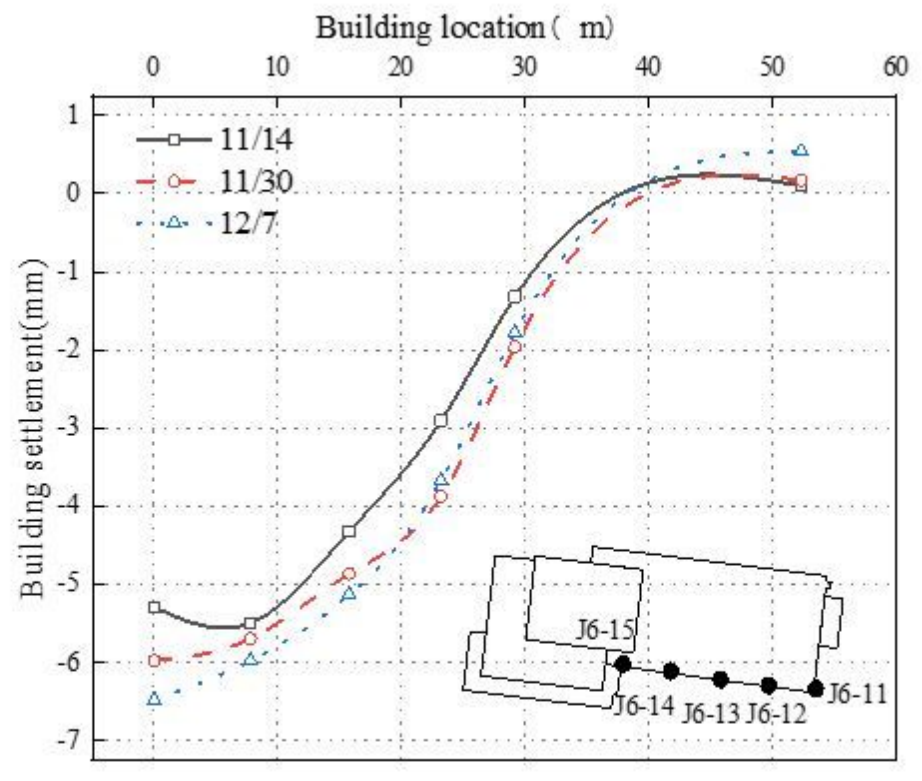

(b) Longitudinal wall of building A

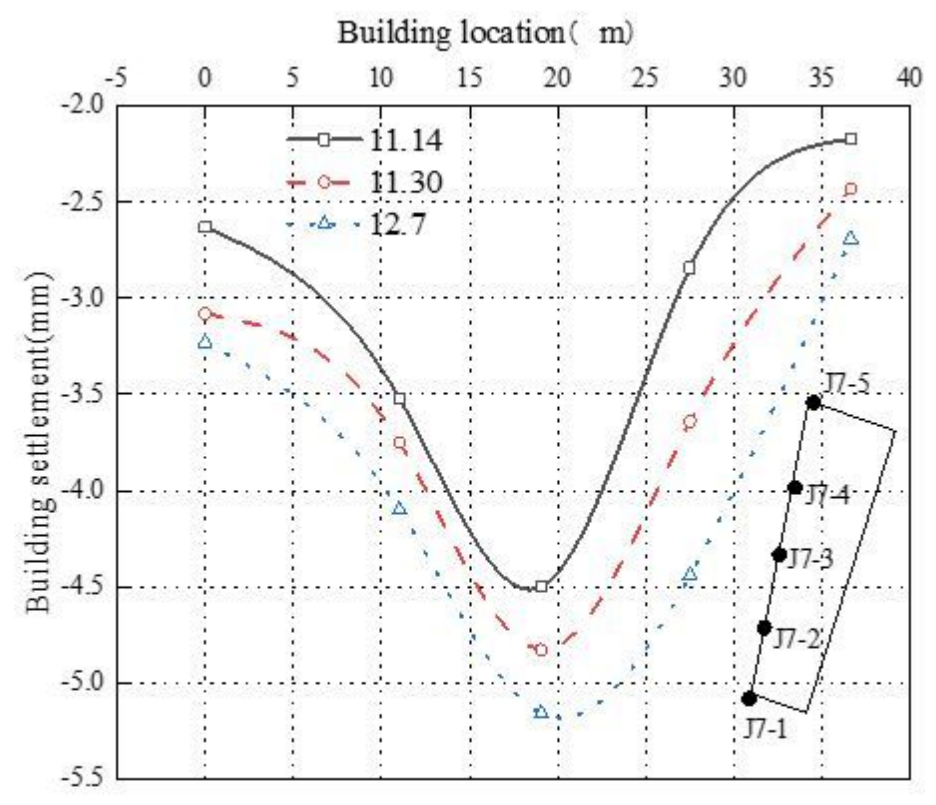

(c) Longitudinal wall of building B

\section{Figure 5}

Building settlement value 


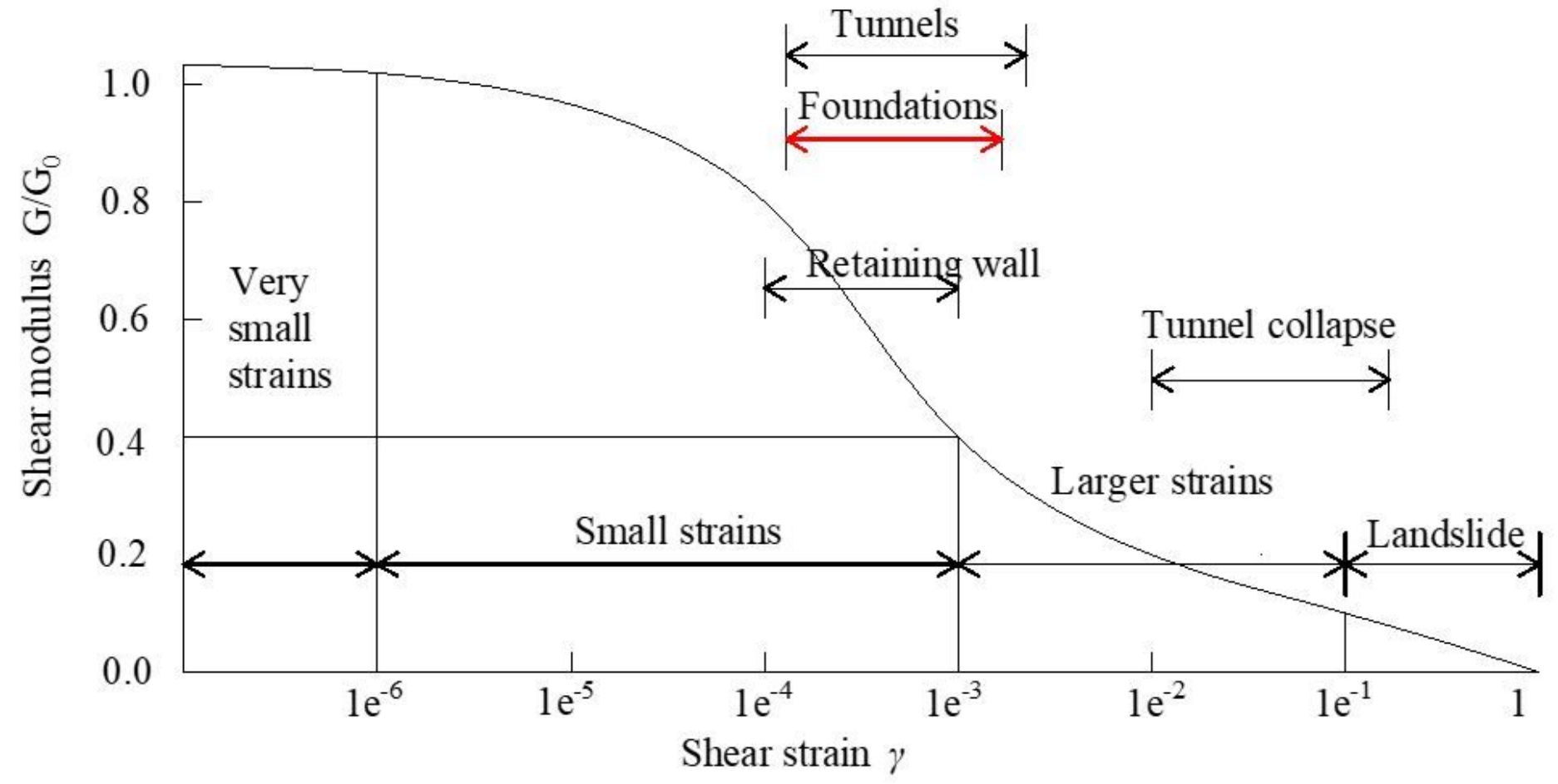

Figure 6

Common geotechnical engineering strain range 


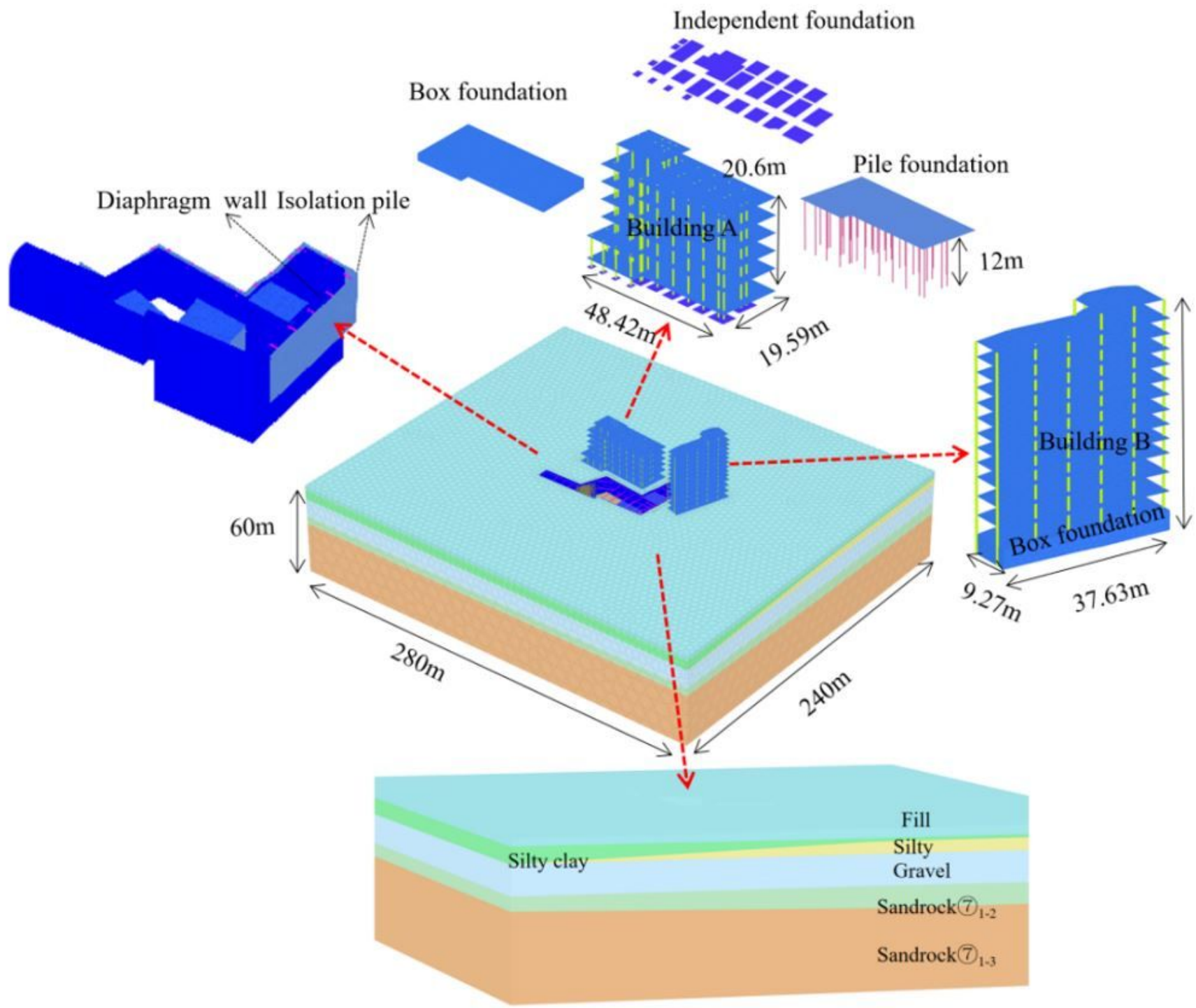

$41.4 \mathrm{~m}$

Figure 7

Calculation mode of the three-dimensional finite element 


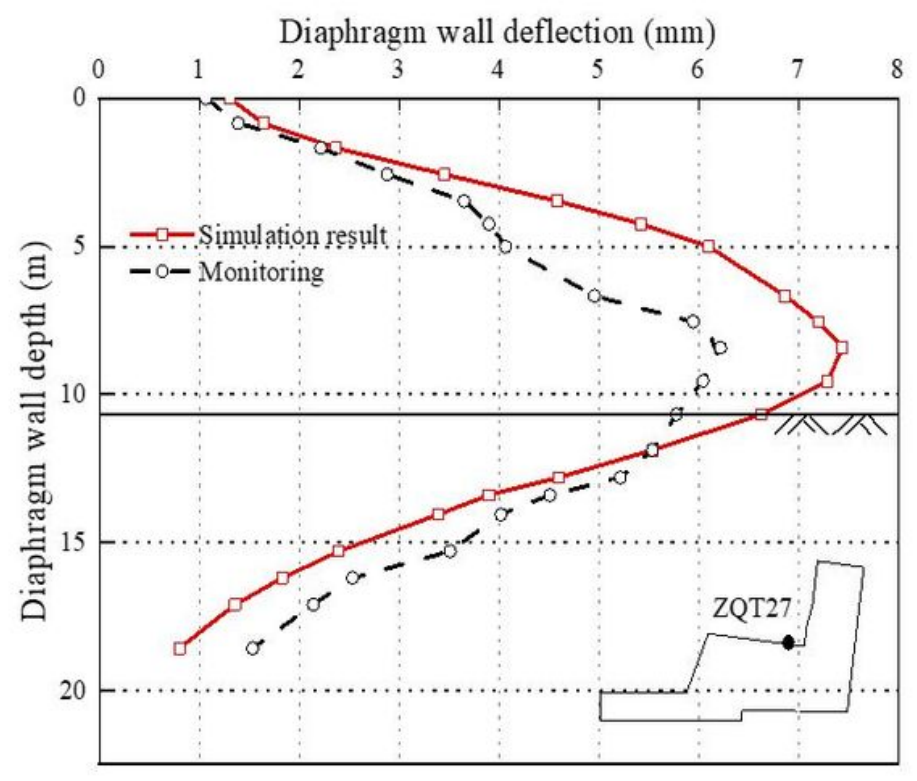

(a) ZQT27

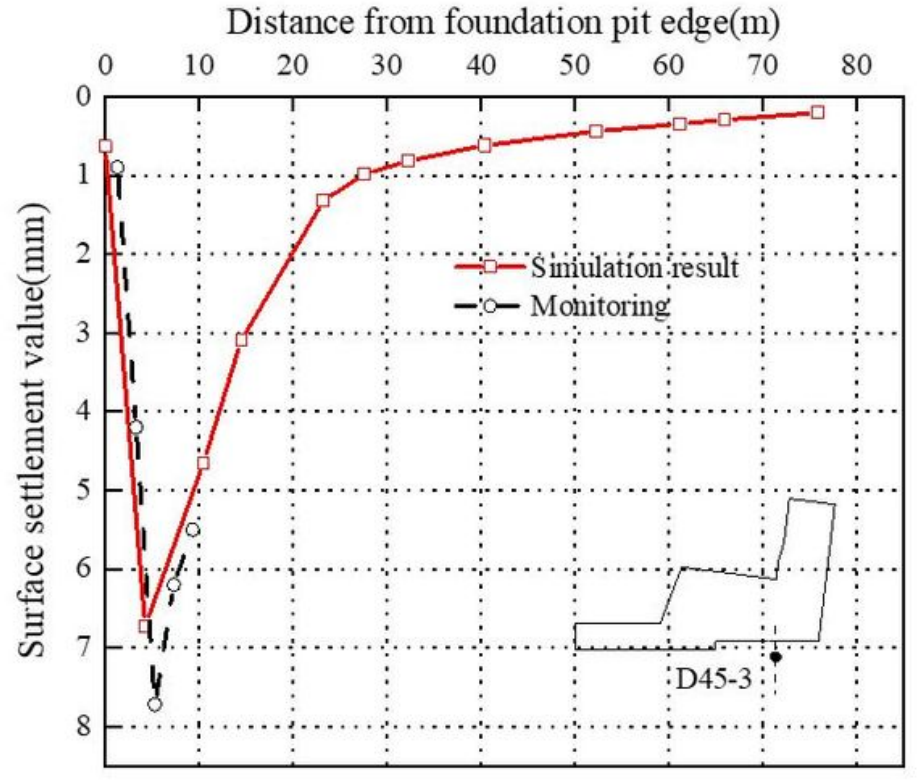

(b) $\mathrm{D} 45-3$

\section{Figure 8}

Lateral wall displacement and surface settlement 


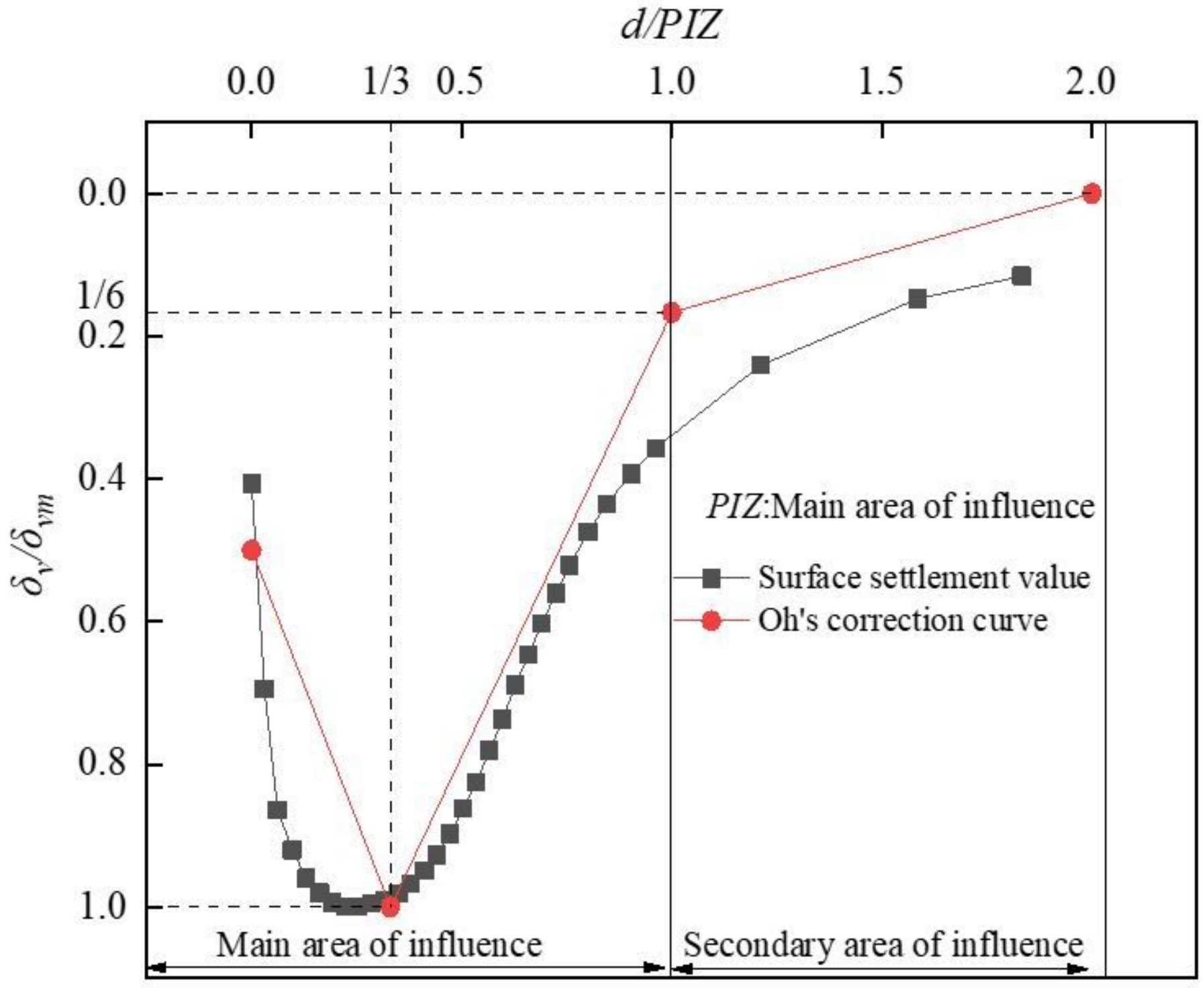

Figure 9

Comparison of calculated values and Ou's experience curve 


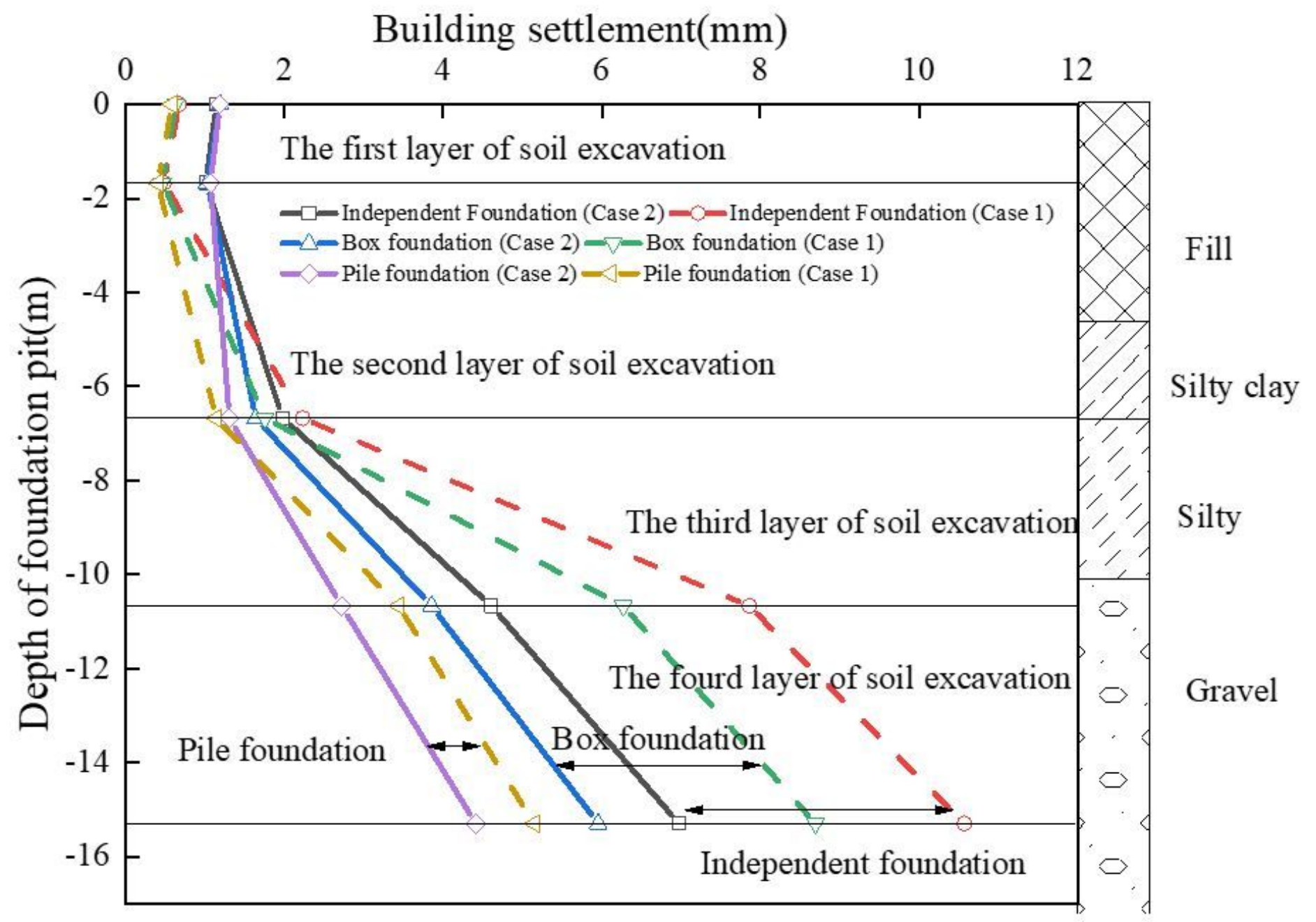

Figure 10

Maximum settlement value of the building 


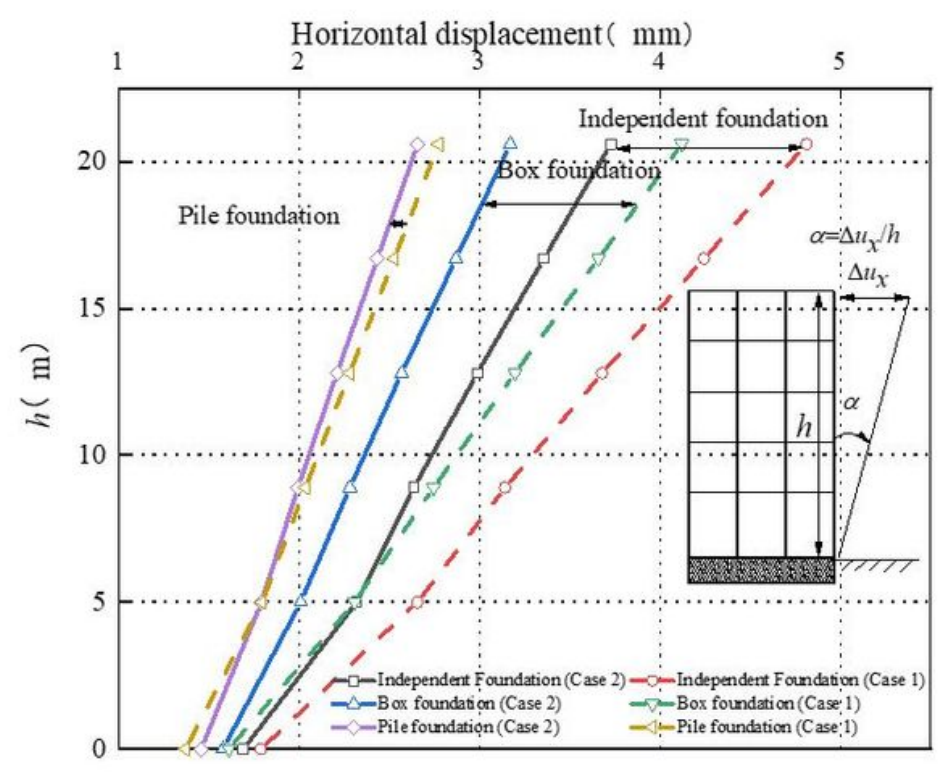

(a) $u_{\mathrm{x}}$ direction

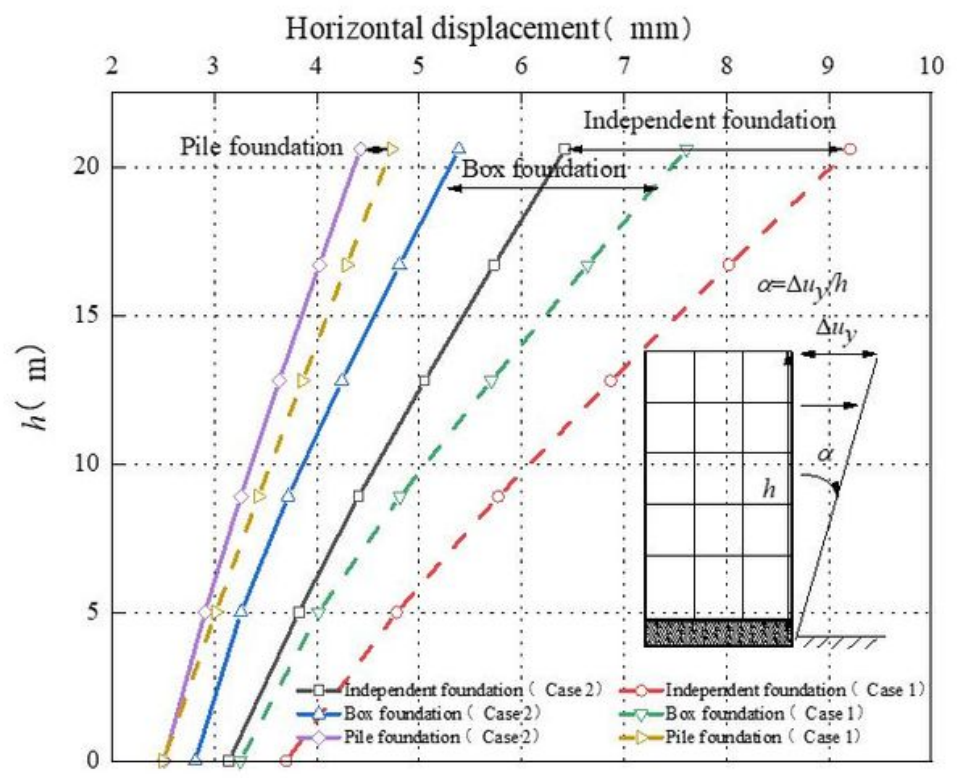

(b) $u_{\mathrm{y}}$ direction

\section{Figure 11}

Maximum horizontal displacement of the building

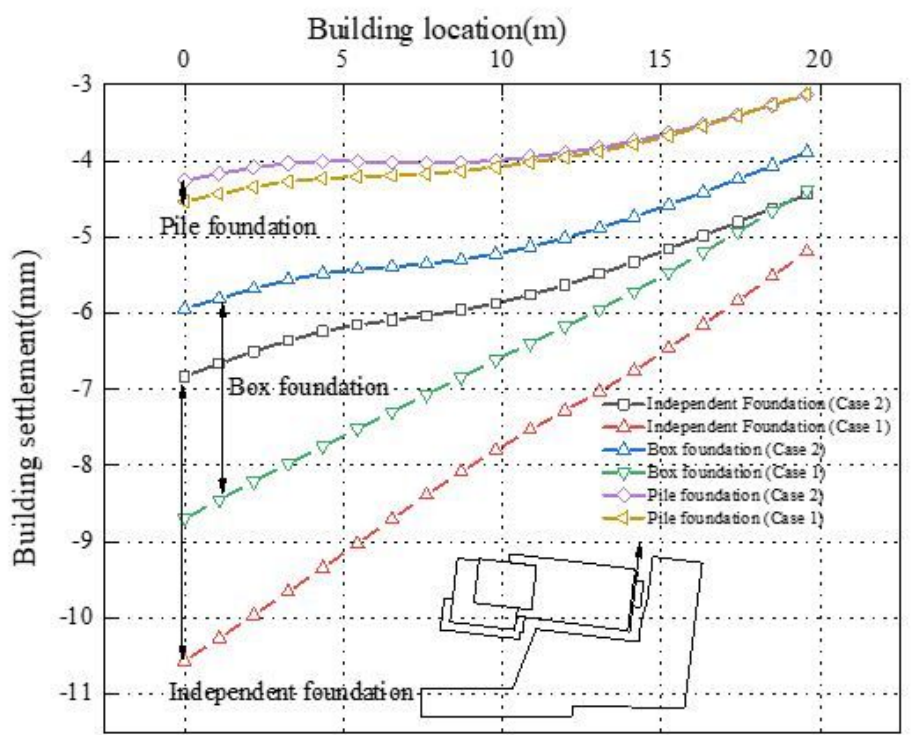

(a) Settlement value of the short side

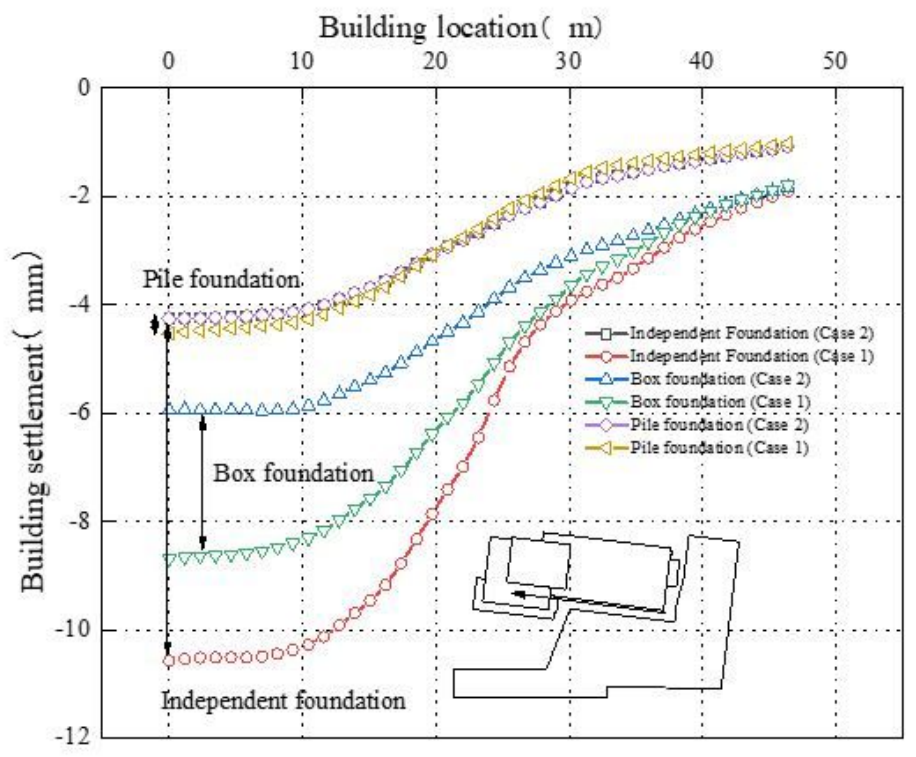

(b) Settlement value of the long side

Figure 12

Settlement values of short and long sides of buildings 


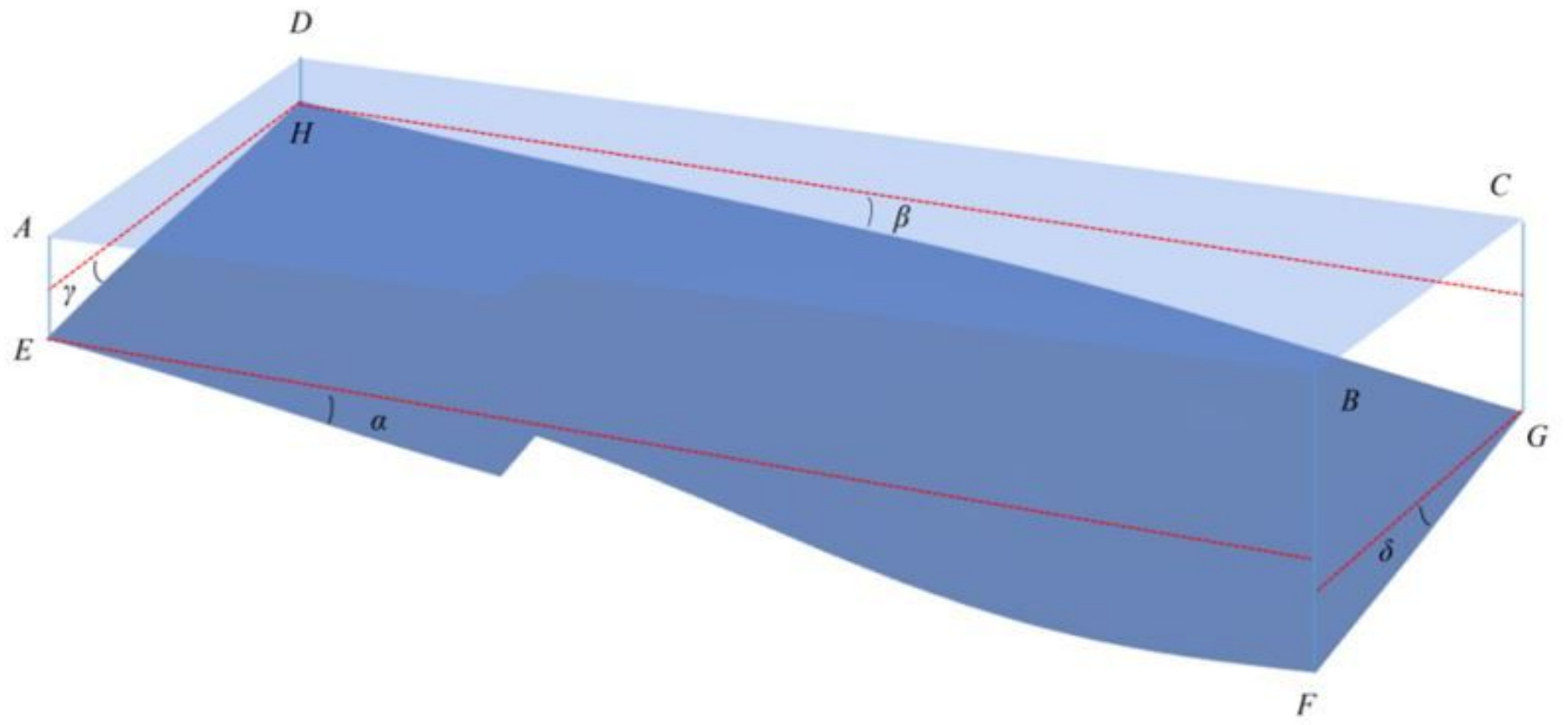

\section{Figure 13}

Schematic diagram of angular distortions of buildings

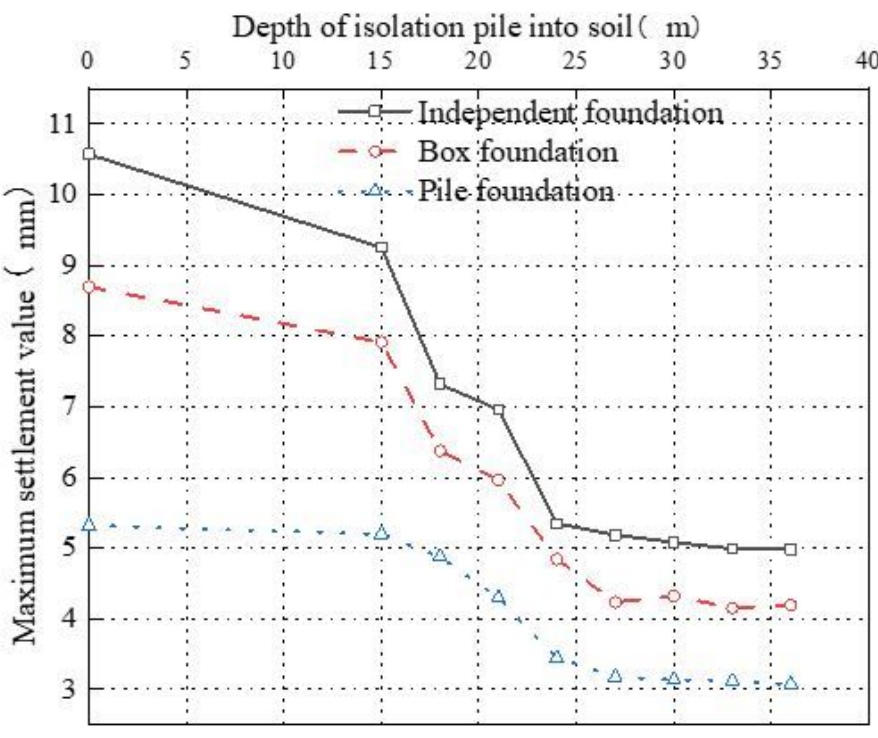

(a) Maximum settlement value

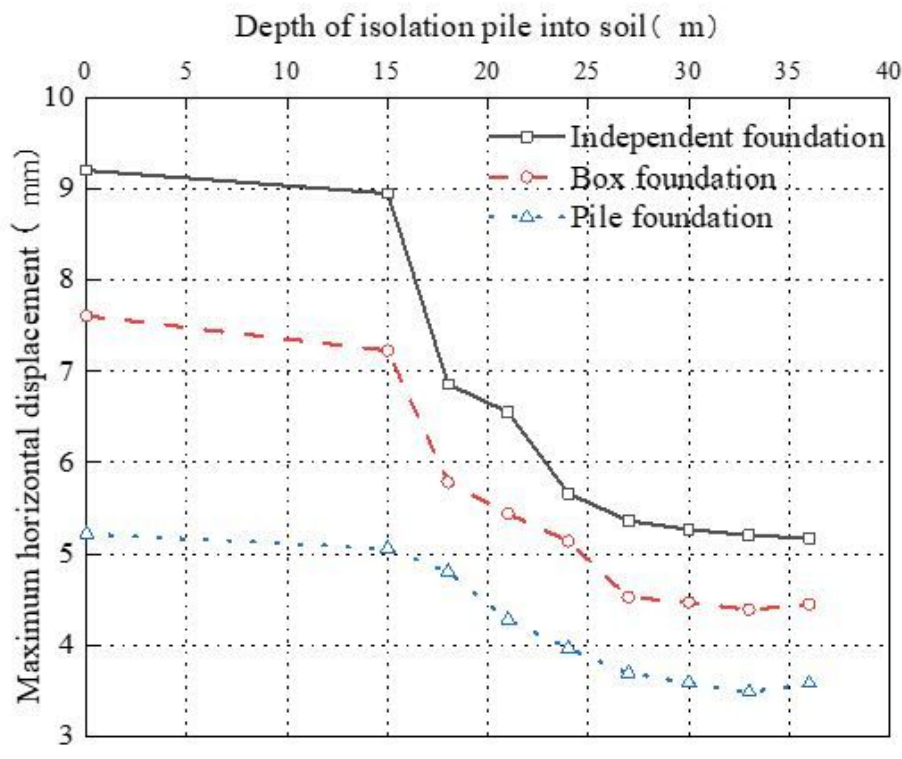

(b) Maximum horizontal displacement

\section{Figure 14}

Influence of isolation pile length on settlement value and horizontal displacement of different types of foundations 


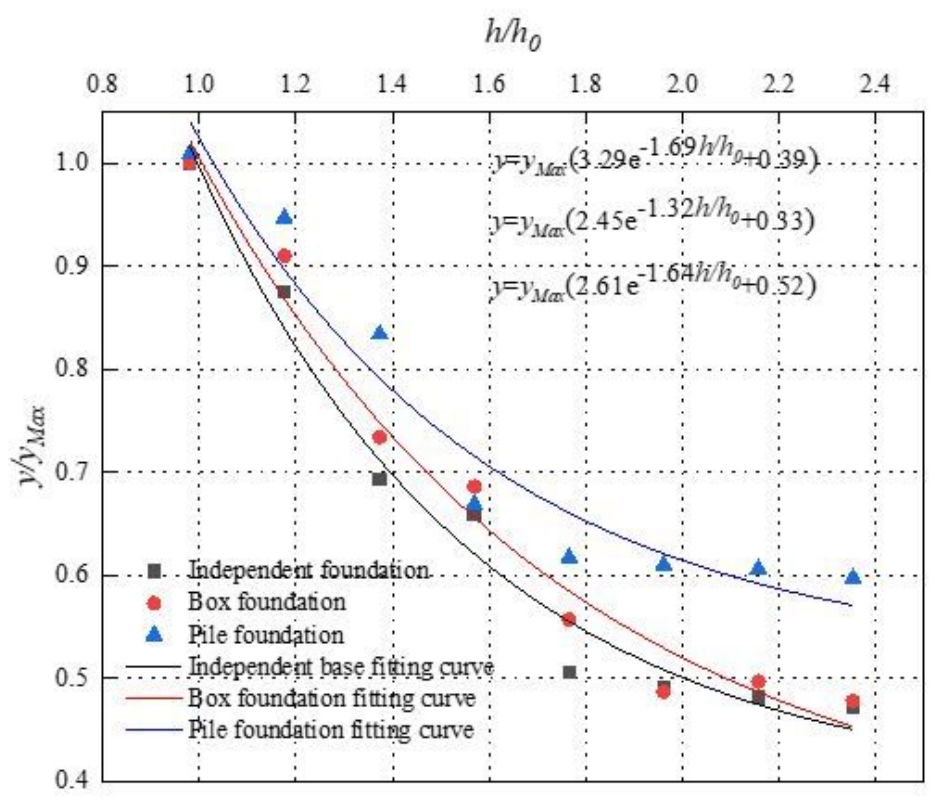

(a) Maximum settlement value

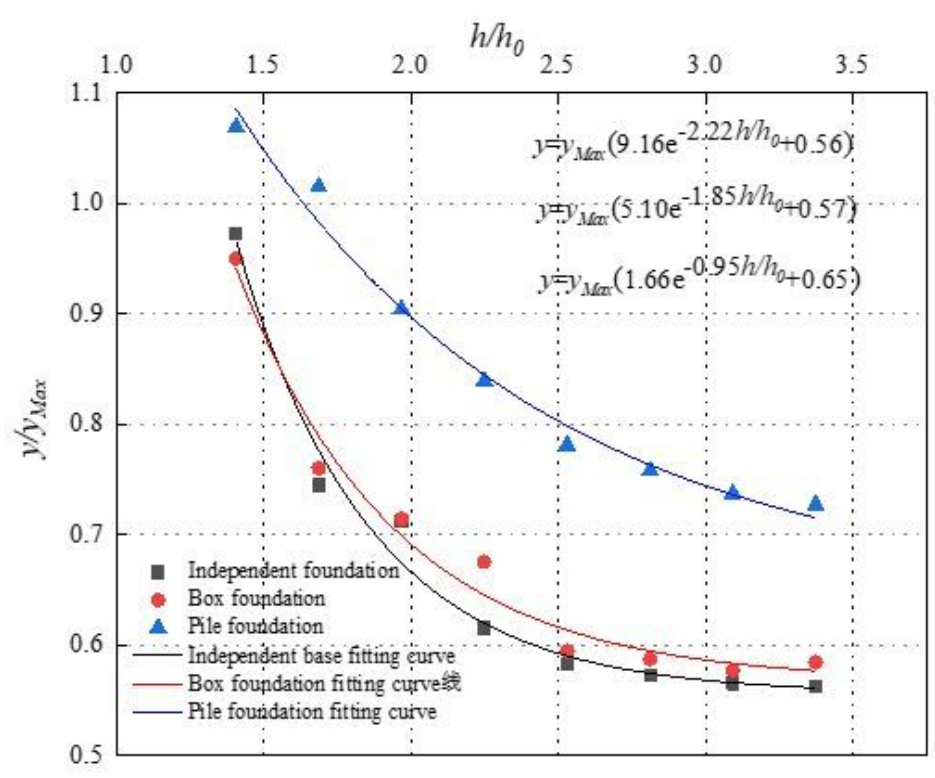

(b) Maximum horizontal displacement value

\section{Figure 15}

Relationship curve between y and $\mathrm{h} / \mathrm{h} 0$ 